\title{
SEDIMENTOS DE FUNDO E EM SUSPENSÃO NO CORREDOR FLUVIAL DO RIO PARAGUAI, PANTANAL NORTE MATO-GROSSENSE, BRASIL
}

\author{
BOTTOM SEDIMENTS AND IN SUSPENSION IN FLUVIAL CORRIDOR OF THE \\ PARAGUAY RIVER, NORTH PANTANAL OF MATO GROSSO, BRAZIL
}

\author{
SEDIMENTOS DEL FONDO Y SÓLIDOS EN SUSPENSIÓN EN EL CORREDOR \\ FLUVIAL DEL RÍO PARAGUAY, PANTANAL NORTE \\ MATO-GROSSENSE, BRASIL
}
Gustavo Roberto dos Santos Leandro - Universidade Federal Fluminense - Niterói - Rio de Janeiro - Brasil gustavogeociencias@hotmail.com
Célia Alves de Souza - Universidade do Estado de Mato Grosso - Cáceres - Mato Grosso - Brasil celiaalvesgeo@globo.com

Flávio Rodrigues do Nascimento - Universidade Federal Fluminense - Niterói - Rio de Janeiro - Brasil flaviogeo@bol.com.br

\begin{abstract}
Resumo
Para a compreensão da variação das descargas sólida e líquida nos períodos de cheia e de estiagem (abril e outubro de 2012), o presente trabalho teve por objetivo analisar os tipos de sedimentos transportados no rio Paraguai - trecho a montante da cidade de Cáceres (MT). A metodologia consistiu em coletas de sedimentos de fundo e em suspensão, monitoramento da vazão e análise de laboratório com pipetagem/peneiramento e evaporação. Os valores de vazão variaram entre $615,12 \mathrm{~m}^{3} / \mathrm{s}^{-1}$ e 135,74 m3/ $/ \mathrm{s}^{-1}$ no rio Paraguai e entre $62,28 \mathrm{~m}^{3} / \mathrm{s}^{-1}$ e $0,71 \mathrm{~m}^{3} / \mathrm{s}^{-1}$ na entrada da baía Comprida, com $56,61 \mathrm{~m}^{3} / \mathrm{s}^{-1}$ na saída dessa baía. Com relação à profundidade média, registrou-se máxima de $4,73 \mathrm{~m}$ e mínima de $0,10 \mathrm{~m}$. 0 s sedimentos de fundo apresentaram maior volume arenoso (concentração acima de $70 \%$ ), com presença de silte e de argila. 0 volume de sólidos suspensos no rio Paraguai variou entre 15.412,44 t/dia e 2.111,02 t/dia. Registraram-se 1.076,08 t/dia e 978,22 t/dia de sólidos suspensos na entrada e na saída do canal da feição morfológica no período de cheia. Cabe salientar que os resultados de vazão foram superiores à média histórica (1966-2002) e os valores dos sedimentos de fundo foram similares aos obtidos por Silva et al. (2008). 0 estudo mostrou-se relevante para a caracterização granulométrica dos sedimentos de fundo, e estimativa do volume de sólidos suspensos transportados pelo rio Paraguai para feições morfológicas da planície de inundação.
\end{abstract}

Palavras-chave: sazonalidade, assoreamento, abandono do canal.

\section{Abstract}

To understand the variation of solid and liquid discharges during flood and drought periods, the present study aimed to analyze the types of sediments transported on the Paraguay River - the upstream in the city of Caceres (MT). The methodology consisted of collections of bottom and suspended sediments, flow monitoring and laboratory analysis with pipetting/screening and evaporation. The flow values ranged from $615,12 \mathrm{~m}^{3} / \mathrm{s}^{-1}$ to $135,74 \mathrm{~m}^{3} / \mathrm{s}^{-1}$ on the Paraguay River and from $62,28 \mathrm{~m}^{3} / \mathrm{s}^{-1}$ to $0,71 \mathrm{~m}^{3} / \mathrm{s}^{-1}$ at the entrance of the Long Bay with $56,61 \mathrm{~m} \mathrm{~m}^{3} / \mathrm{s}^{-1}$ at the exit of the Long Bay. Concerning to the average depth it was recorded a maximum of 4.73 and minimum of $0.10 \mathrm{~m}$. The bottom sediments showed higher sand volume (concentration above $70 \%$ ) with the presence of silt and clay. The volume of suspended solids on the Paraguay River ranged from 15412.44 tons/ day and 2111.02 tons/day. It was registered 1076.08 tons/day and 978.22 tons/day of suspended solids at the entrance and the exit of the channel of the morphological feature in the rainy season. It should be emphasized 
that the results of flow were higher than the historical average (1966-2002) and the values of the bottom sediments were similar to those obtained by Silva et al. (2008). The study proved relevance for the particle size characterization of the bottom sediments, and estimate of the quantity of suspended solids carried by the Paraguay River to morphological features of the floodplain.

Key words: seasonality, siltation, channel abandonment.

\section{Resumen}

El presente estudio examina los tipos de sedimentos transportados en el corredor fluvial del río Paraguay, Cáceres (MT), para la comprensión de los cambios en la acumulación y almacenamiento. La metodología consistió en muestras de sedimento, monitoreo de flujo y análisis de laboratorio con pipeteo/proyección y evaporación. Los valores oscilaron entre $615.12 \mathrm{~m}^{3} / \mathrm{s}^{-1}$ y $135.74 \mathrm{~m}^{3} / \mathrm{s}^{-1}$ en el río Paraguay y $62.28 \mathrm{~m}^{3} / \mathrm{s}^{-1}$ y $0.71 \mathrm{~m}^{3} / \mathrm{s}^{-1}$ en la entrada con $56,61 \mathrm{~m}^{3} / \mathrm{s}^{-1}$ y en el canal de salida de Baía Comprida, donde estaba registrado en la estación seca. Con relación a la profundidad máxima registrada promedio $4,73 \mathrm{~m}$ y un mínimo de 0,10 $\mathrm{m}$. Los sedimentos de la parte inferior presentan un volumen más alto con la presencia de limo arenoso y arcillas. El volumen de sólidos suspendidos en el río Paraguay oscilan entre 15.412 toneladas/día y 2.111.02 t/día registrados. El volumen el Baía Comprida oscilan entre 1.076 t/día y 978.22 t/día de sólidos suspendidos en la entrada y salida del canal, unidad geomorfológica en periodo de las aguas crecidas del río. El estudio resultó relevante para la caracterización de tamaño de partículas de sedimentos del fondo y estimar el volumen de sólidos en suspensión transportados y transferido por el río Paraguay a las características morfológicas de la llanura aluvial.

Palabras clave: estacionalidad, sedimentación, abandono del canal.

Introdução

O corredor fluvial do rio Paraguai caracteriza-se como uma unidade de sedimentação do Pantanal Mato-Grossense. A dinâmica do canal principal atua como fator controlador da evolução de feições morfológicas, tais como baías e lagoas, com importância no que se refere também à biodiversidade, ao turismo e à navegação como práticas sociais. Nesse sentido, a água assume papel relevante, associado aos processos de erosão, transporte e deposição de sedimentos na planície de inundação e baixo curso dos afluentes.

De acordo com Suguio (1973, p. 38), utiliza-se o termo granulometria como referência ao diâmetro dos grãos, e as finalidades das análises granulométricas variam de acordo com o campo da atividade no qual elas estão empregadas. A análise granulométrica de partículas sólidas compreende a determinação do tamanho desses materiais, bem como da frequência em que ocorrem em uma determinada classe ou faixa de tamanho em diversos ambientes, como os fluviais.

Dessa forma, a carga de fundo, juntamente com a carga suspensa, é extremamente importante nos processos fluviais, e seu conhecimento é imprescindível ao gerenciamento de um rio. Tal combinação controla a morfologia e o padrão do canal, as características da planície de inun- 
dação, além de interferir na ecologia e no uso da água fluvial (Leli et al., 2010, p. 52).

Souza Filho (2013, p. 131) destaca que a descontinuidade de dados referentes à descarga fluvial e ao transporte de sedimentos, associada aos impactos do uso e ocupação do solo na bacia hidrográfica do rio Paraguai, indicam a necessidade de monitoramentos, especialmente do transporte de leito, que nunca foi monitorado de forma sistemática. $\mathrm{O}$ autor salienta ainda possíveis consequências dos empreendimentos hidrelétricos em diferentes fases na bacia, relacionados às barragens com retenção de sedimentos, o que proporcionará o ajuste fluvial dos canais situados a jusante das barragens. E esse efeito será particularmente forte nos segmentos que desenvolvem leques aluviais.

A análise da concentração de sólidos em suspensão em ambiente fluvial e lacustre, conforme Braga (2013, p. 122), "é de fundamental importância para que se possam realizar estudos visando ao planejamento ordenado do uso da terra e dos recursos hídricos de uma bacia hidrográfica”. O autor destaca ainda que a quantidade de sólidos carregados gera problemas como a erosão, deposição e compactação e o transporte, além de determinar, por exemplo, a vida útil de empreendimentos hidráulicos, a possibilidade de aproveitamento para transporte hidroviário. E ainda é parâmetro de qualidade da água para o consumo humano.

Trabalhos recentes sobre a distribuição e a composição granulométrica de sedimentos, em ambientes fluviais do rio Paraguai, têm sido desenvolvidos com a finalidade de se compreenderem mudanças quanto ao armazenagem e à deposição (Souza, 2004; Silva, 2006; Silva et al., 2008; Leandro e Souza, 2012; Leandro et al., 2012; Bühler e Souza, 2012; Souza et al., 2012). Dentro desse contexto, o presente estudo objetivou analisar a granulometria dos sedimentos de fundo e verificar a concentração em suspensão no corredor fluvial do rio Paraguai, Pantanal Norte Mato-Grossense, para os períodos de estiagem e de cheia, abril e outubro de 2012, respectivamente.

\section{Material e métodos}

O município de Cáceres, em Mato Grosso, encontra-se inserido em áreas de cerrado, floresta e, em sua maioria, em área de pantanal (cerca de 50,87\%). As sub-regiões dos pantanais de Cáceres e Poconé, no município de Cáceres, abrangem aproximadamente 9,01\% da área total do Pantanal 
Mato-Grossense. E, da área total do Pantanal de Cáceres, 99,66\% encontram-se no município de respectivo nome, enquanto o restante encontra-se inserido nos municípios de Curvelândia (0,04\%) e Lambari d'Oeste (0,3\%) (Neves et al., 2009, p. 796). O rio Paraguai, principal contribuinte desse sistema, percorre o território de norte para sul e recebe alguns de seus principais afluentes no Pantanal de Cáceres.

O sistema fluvial drena aluviões atuais caracterizados por depósitos recentes de areias, siltes, argilas e cascalhos, e a área está embasada nos sedimentos da Formação Pantanal (Souza, 2004, p. 15). Geomorfologicamente, o rio Paraguai encontra-se na Depressão do Alto rio Paraguai e em áreas de planícies (Souza, 2004, p. 23). Conforme Camargo (2011, p. 41), a Morfoestrutura refere-se à dos sedimentos da bacia do rio Paraguai com Morfoescultura das Planícies Fluviais do rio Paraguai ou Planície Aluvionar Meandriforme.

A análise dos dados de precipitação, para o período de 1971-2009, do município de Cáceres mostra um total anual de $1.335 \mathrm{~mm}$; entretanto, o período de maior concentração pluvial média (62,68\%) ocorre de dezembro a março. Ainda em relação à precipitação, medições mostram que o mês mais chuvoso é janeiro e que o período de seca é de oito meses (abril a novembro), sendo mais intenso de junho a agosto, com apenas 4,9\% do total pluviométrico anual (Neves et al., 2011, p. 59).

O tipo de solo predominante é o Gleissolo Háplico Eutrófico, caracterizado como solo de áreas úmidas de textura arenosa em relevo plano. São ambientes de drenagem que, por ocasião das cheias, sempre recebem material, depositando-o em diferentes camadas, onde os fatores de formação não tiveram tempo suficiente para promover o desenvolvimento de horizontes, como a sequência do tipo A, B e C, A, condição incipiente na formação do solo supracitado e que tem grande influência sobre sua instabilidade aos processos erosivos (Souza, 2004, p. 32; Camargo, 2011, p. 43).

As características da planície contribuem para a ocorrência de inundação de forma diferenciada em razão da altura do nível da água e ao tempo (meses) em que a planície permanece alagada, o que possibilita o desenvolvimento de diferentes formações vegetais: Contato Floresta Estacional/Savana, Floresta Aluvial e Savana Arborizada com Floresta Galeria (Souza, 2004, p. 33-34; Camargo, 2011, p. 58-59). Castrillon et al. (2011, p. 672) associam a heterogeneidade de habitat à ampla distribuição de espécies vegetais, ao pulso de inundação que pode estar sendo controlada 
pela dinâmica fluvial e às diferenças na origem geomorfológica do rio Paraguai, com ambientes de sedimentação arenoso, silto-argiloso.

A área da pesquisa compreende um trecho do corredor fluvial do rio Paraguai e da baía Comprida e encontra-se entre as coordenadas ge-

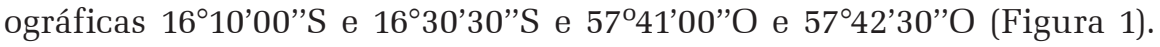
A baía Comprida é um canal secundário do rio Paraguai, que abastece alguns canais do complexo de baías localizadas no perímetro urbano de Cáceres, Mato Grosso. Com os ciclos de cheia e de estiagem, o sistema hidrográfico recebe parte da carga líquida e sólida, transportada pelo rio Paraguai, o que, conforme verificado por Silva et al. (2012, p. 441), no período de estiagem, resulta na deposição de sedimentos arenosos no canal e de sedimentos finos na planície de inundação. Tais processos caracterizam o comportamento do sistema rio-planície no corredor fluvial do rio Paraguai no Pantanal de Cáceres, Mato Grosso.
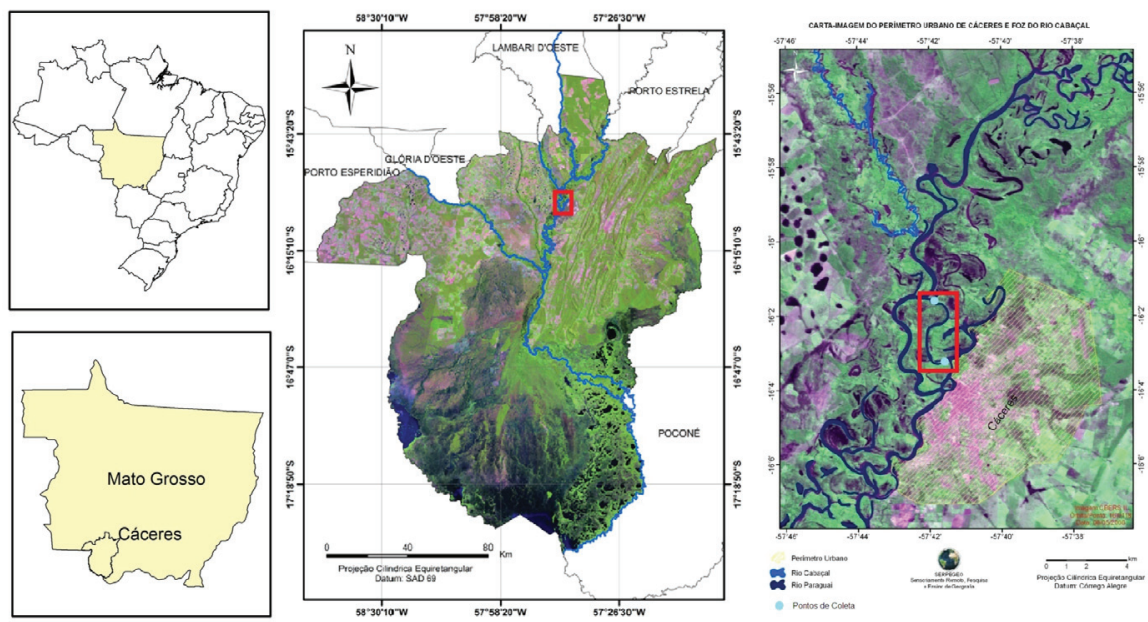

Figura 1 - Carta imagem do sistema hidrográfico do rio Paraguai; Cáceres, Mato Grosso Fonte: Elaboração dos autores a partir de imagem LANDSAT.

\section{Procedimentos metodológicos}

\section{Amostragem de sedimentos de fundo e em suspensão}

As coletas dos sedimentos de fundo ocorreram nos períodos de cheia e de estiagem (abril e outubro de 2012). Para tanto, utilizou-se o 
aparelho do tipo Van Veen (amostrador de mandíbulas). O aparelho foi lançado no canal até alcançar o fundo, retendo carga sólida em suas mandíbulas (Figura 2). Rocha e Souza Filho (2005, p. 21) destacam que esse tipo de pegador permite coletar uma camada do leito de cerca de $10 \mathrm{~cm}$, quando em sedimentos incoesos.

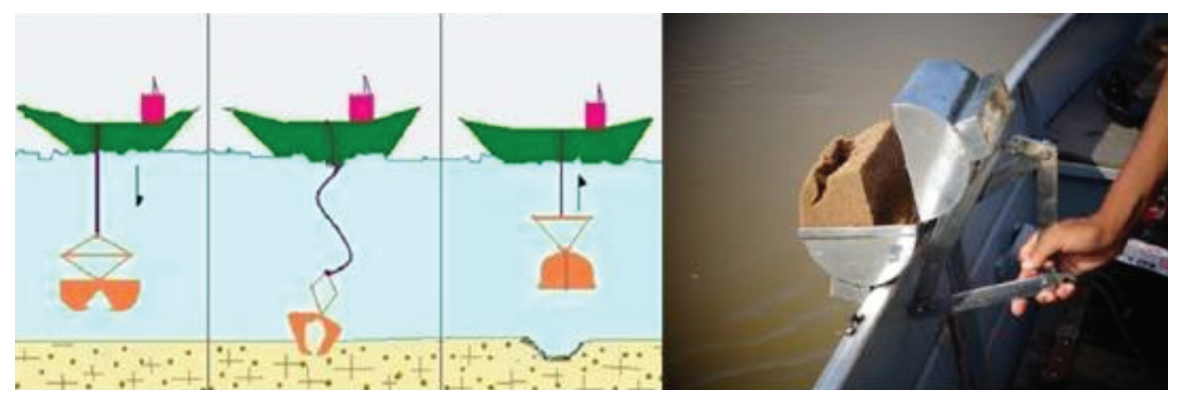

Figura 2 - llustração do procedimento de coleta dos sedimentos de fundo. Fonte: Franco (2007).

Conforme Carvalho (2008, p. 79), para se estabelecer uma média da velocidade da correnteza de forma coerente, é necessário realizar medições da velocidade do fluxo em diferentes seções transversais ao canal e, em cada seção, medir em diferentes verticais (profundidades diferentes). Nesse sentido, in loco obtiveram-se dados referentes à largura/profundidade do canal com o auxílio de GPSmaps GARMIN 420s com ecobatímetro, e referentes à velocidade com o molinete hidrométrico modelo CPD-10.

Para a coleta dos sedimentos em suspensão, foram utilizadas garrafas plásticas de 1 litro. Primeiramente, as garrafas foram enxaguadas duas vezes com a água do próprio rio. Em seguida, foram mergulhadas a 20 cm da coluna d'água para o recolhimento do material. $\mathrm{O}$ armazenamento posterior, até o início das análises (máximo de 24 horas após coleta), foi efetuado em caixa de isopor com gelo (Bühler e Souza, 2012, p. 340-342).

\section{Análise de laboratório}

As análises foram realizadas no Laboratório de Pesquisa e Estudos em Geomorfologia Fluvial (LAPEGEOF), da Universidade do Estado de Mato Grosso (UNEMAT). 


\section{Ensaio de pipetagem (dispersão total)}

Para quantificar as frações de argila e de silte, utilizou-se o processo da pipetagem (EMBRAPA, 1997, p. 27-32), utilizando-se amostras de $20 \mathrm{~g}$ de sedimentos, que foram mantidas por 12 horas em contato com a solução de um dispersante químico $\left(\mathrm{NaOH} 0,1 \mathrm{M} \cdot \mathrm{L}^{-1}\right)$; posteriormente, foram agitadas em alta rotação (12.000 rpm) por 15 minutos. A fração de argila foi determinada pelo método da pipeta, que consiste em pipetar um volume da suspensão que é seca em estufa. A fração de areia foi retida em peneira de malha de 0,053 mm (n. 270). As frações foram secas em estufa e pesadas para a obtenção dos respectivos percentuais. O silte corresponde ao complemento dos percentuais para $100 \%$, que é obtido por diferença das outras frações em relação ao peso da amostra original. Foram realizados três ensaios por ponto de coleta para obtenção da composição média dos sedimentos de fundo.

\section{Ensaio de peneiramento}

A quantificação das frações de areia (grossa, média e fina) foi obtida com o peneiramento. O material retido pela pipetagem (dispersão total), na peneira de $20 \mathrm{~cm}$ de diâmetro e malha de 0,053 (n. 270), foi seco em estufa. Posteriormente, foi submetido a processo mecânico no agitador eletromagnético, com uma sequência de peneiras padronizadas, por 30 minutos. O material retido em cada uma das peneiras foi pesado separadamente (Suguio, 1973, p. 38).

A areia retida nas peneiras de 4,75 $\mathrm{mm}$ e 2,36 $\mathrm{mm}$ foi considerada grossa; aquela que passou pela peneira de $2,36 \mathrm{~mm}$, mas ficou retida nas peneiras de 1,18 $\mathrm{mm}$ e $600 \mu \mathrm{m}$, foi considerada média, e, finalmente, a areia retida nas peneiras de $300 \mu \mathrm{m}$ a $75 \mu \mathrm{m}$ foi classificada como fina. Essa escala foi adaptada da American Society for Testing and Materiais (ASTM), conforme Souza et al. (2012, p. 87).

\section{Pesagem dos sedimentos suspensos}

A quantidade de sedimento suspenso pode ser obtida indiretamente por: 1) filtração, 2) evaporação e 3) granulômetro a laser. Em quaisquer dos métodos utilizados, as amostras coletadas são armazenadas em geladeira 
e ao abrigo de luz para evitar proliferação de algas. No presente trabalho, adotou-se a evaporação. De acordo com esse método, determinado volume de amostra é posto em um Becker pré-pesado e levado à estufa modelo TE-394/2 $\left(65^{\circ} \mathrm{C}\right)$ para que a umidade seja totalmente extraída do material, principalmente se o material for argila. Por diferença, obtém-se a quantidade de sedimento em suspensão, representado em $\mathrm{mg} / \mathrm{L}^{-1}$ (Leli et al., 2010, p. 55-56).

\section{Trabalho de gabinete}

Conforme Ross e Fierz (2009, p. 69), o trabalho de gabinete constitui-se, sobretudo, da elaboração do projeto, das pesquisas e da interpretação de dados. Os dados de campo e de laboratório sistematizados com o auxilio do software Excel 2010 contribuíram para o cálculo do volume de água e sedimentos transportados em seções transversais do rio Paraguai (Seção A) e da baía Comprida (Seções B e C) nos períodos de cheia e de estiagem (Figura 3).

\section{Cálculo de vazão e de descarga sólida em suspensão}

Os valores da área da seção molhada foram obtidos com a fórmula: A = L x P, em que: A = Área da seção; L = Largura do canal; P = Profundidade média. Para obter o cálculo da vazão, utilizou-se a seguinte fórmula: $\mathrm{Q}=\mathrm{V}$ x A, em que: $\mathrm{Q}=$ Vazão; $\mathrm{V}=$ Velocidade das águas; $\mathrm{A}=$ Área (Cunha, 2009, p. 157-167). E os valores de descarga sólida em suspensão $\left(Q_{S S}\right)$ foram determinados pelo somatório do produto entre a concentração de sedimento suspenso da vertical $\left(\mathrm{C}_{\mathrm{SSi}}\right)$, respectiva descarga líquida da vertical $\left(\mathrm{Ql}_{\mathrm{i}}\right)$ e segundos totais em 24 horas (86400), na forma da expressão abaixo:

$$
Q_{S S}=\Sigma\left(C_{S S i} \cdot Q l_{i}\right) \cdot 0,0864
$$

Em que: $\mathrm{Q}_{\mathrm{SS}}=$ descarga sólida em suspensão $\left(\mathrm{t}\right.$ dia $\left.^{-1}\right) ; \mathrm{C}_{\mathrm{SSi}}=$ concentração de sedimento em suspensão da vertical $\left(\mathrm{mg} / \mathrm{L}^{-1}\right) ; \mathrm{Ql}_{\mathrm{i}}=$ descarga líquida da respectiva vertical $\left(\mathrm{m}^{3} / \mathrm{s}^{-1}\right)$; e $0,0864=$ total de segundos/dia (Carvalho, 2009, p. 152). 


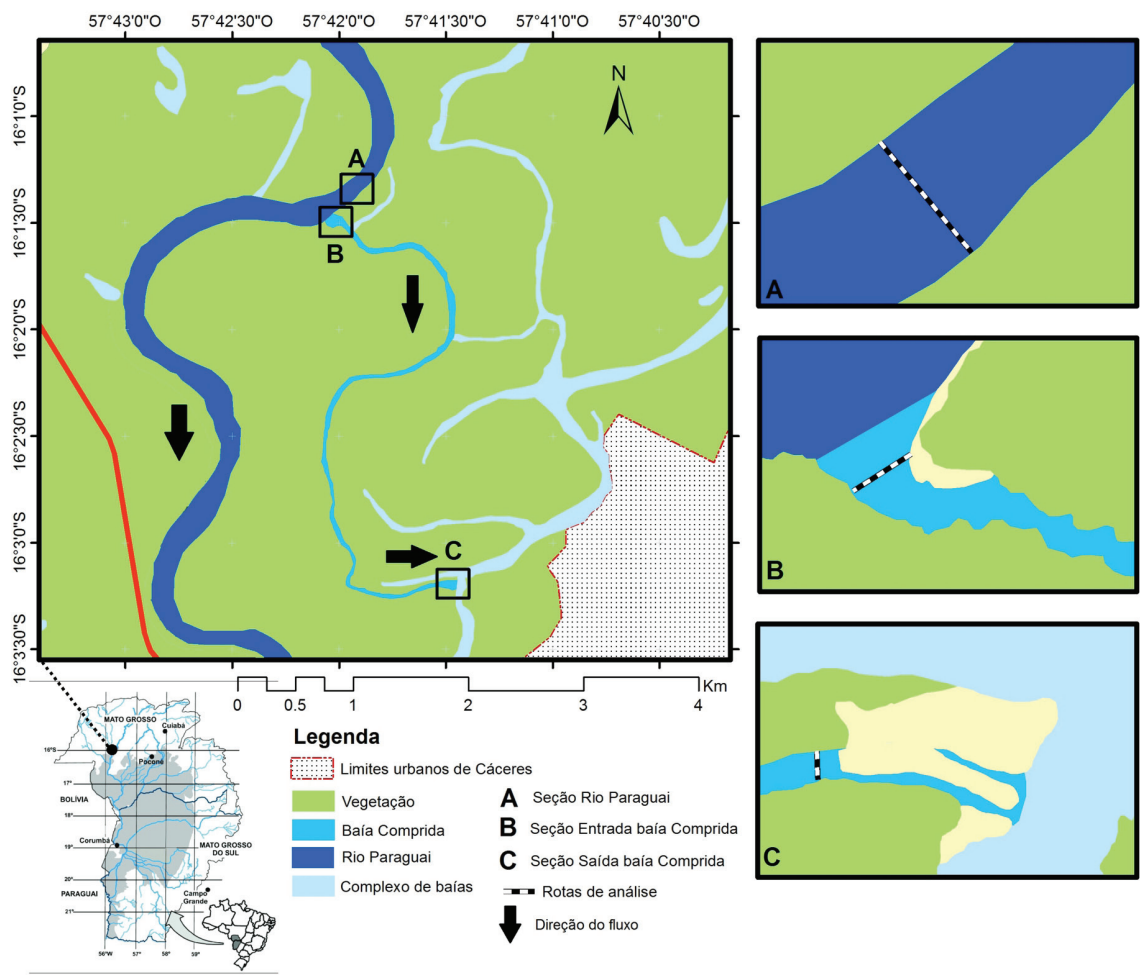

Figura 3 - Sistema hidrográfico do rio Paraguai e localização das seções monitoradas Cáceres, Mato Grosso.

Fonte: Elaboração dos autores a partir de imagem LANDSAT.

\section{Resultados e discussão}

A Tabela 1 apresenta os dados obtidos sobre os sedimentos em suspensão e hidrodinâmica no corredor fluvial. No canal principal do rio Paraguai, a vazão e a descarga sólida foram superiores aos valores obtidos na baía Comprida, canal secundário.

Com relação à profundidade média, obteve-se máxima de $4,73 \mathrm{~m}$ e mínima de 0,10 m. Os valores de vazão variaram entre $615,12 \mathrm{~m}^{3} / \mathrm{s}^{-1} \mathrm{e}$ $135,74 \mathrm{~m}^{3} / \mathrm{s}^{-1}$ no rio Paraguai. Na entrada da baía Comprida o valor diminuiu de $62,28 \mathrm{~m}^{3} / \mathrm{s}^{-1}$ para $0,71 \mathrm{~m}^{3} / \mathrm{s}^{-1}$, e na saída dela registrou-se $56,61 \mathrm{~m}^{3} / \mathrm{s}^{-1}$ no período de cheia. No período de estiagem, a vazão não foi registrada 
na saída da baía Comprida, pois ocorreu o assoreamento do canal. Vale ressaltar ainda que a altura da lâmina de escoamento, para os eventos de cheia e de estiagem, variou de 1,96 $\mathrm{m}$ a $0,10 \mathrm{~m}$, e a largura do canal diminuiu de $54,5 \mathrm{~m}$ para $12,55 \mathrm{~m}$ (Tabela 1).

Tabela 1 - Amplitude das variáveis hidrodinâmicas obtidas no corredor fluvial do rio Paraguai para os períodos de cheia (abril de 2012) e de estiagem (outubro de 2012);

Cáceres, Mato Grosso.

\begin{tabular}{|l|c|c|c|c|c|c|c|c|}
\hline Local & Período & Largura & $\begin{array}{c}\text { Prof. } \\
\mathbf{M}\end{array}$ & $\begin{array}{c}\text { Velocidade } \\
\mathbf{m} / \mathbf{s}^{-1}\end{array}$ & $\begin{array}{c}\text { Área } \\
\mathbf{m}^{\mathbf{2}}\end{array}$ & $\begin{array}{c}\text { Vazão } \\
\mathbf{m}^{3} / \mathbf{s}^{-1}\end{array}$ & $\begin{array}{c}\text { Suspensão } \\
\mathbf{m g} / \mathbf{L}^{-1}\end{array}$ & $\begin{array}{c}\text { Descarga } \\
\mathbf{s o ́ l i d a ~} \\
\mathbf{t} / \mathbf{d i a}\end{array}$ \\
\hline $\begin{array}{l}\text { Rio Paraguai - } \\
\text { montante baía } \\
\text { Comprida } \\
\text { (Seção A) }\end{array}$ & Cheia & 175,74 & 4,73 & 0,74 & 831,25 & 615,12 & 290 & $15.412,44$ \\
\cline { 2 - 9 } & Estiagem & 148,15 & 2,73 & 0,33 & 404,44 & 135,74 & 180 & $2.111,02$ \\
\hline $\begin{array}{l}\text { Entrada da } \\
\text { baía Comprida } \\
\text { (Seção B) }\end{array}$ & Cheia & 47,71 & 2,72 & 0,48 & 129,77 & 62,28 & 200 & $1.076,08$ \\
\cline { 2 - 9 } & Estiagem & 24 & 0,27 & 0,11 & 6,48 & 0,71 & --- & --- \\
\hline $\begin{array}{l}\text { Saída da baía } \\
\text { Comprida } \\
\text { (Seção C) }\end{array}$ & Cheia & 54,5 & 1,96 & 0,53 & 106,82 & 56,61 & 200 & 978,22 \\
\cline { 2 - 9 } & Estiagem & 12,55 & 0,10 & --- & 1,25 & --- & --- & --- \\
\hline
\end{tabular}

Fonte: Elaboração dos autores.

A vazão obtida no rio Paraguai, durante o período de cheia, foi superior à média histórica $\left(537 \mathrm{~m}^{3} / \mathrm{s}^{-1}\right.$ para o período de 1966-2002) registrada na Estação de Cáceres (Código 66070004); contudo, quando esses resultados foram comparados com as vazões máxima e mínima, os valores obtidos no presente estudo ficaram abaixo da média histórica $\left(133 \mathrm{~m}^{3} / \mathrm{s}^{-1}\right.$ - $2.659 \mathrm{~m}^{3} / \mathrm{s}^{-1}$ ) à exceção da vazão registrada no rio Paraguai, no período de estiagem (Silva, 2006, p. 18).

Na entrada da baía Comprida, a seção transversal apresentou largura entre $47,71 \mathrm{~m}$ e $24 \mathrm{~m}$, onde foi registrada a diminuição na profundidade do canal de $2,72 \mathrm{~m}$ para $0,27 \mathrm{~m}$. A área da seção variou entre 6,48 $\mathrm{m}^{2}$ e $129,77 \mathrm{~m}^{2}$, enquanto a velocidade do fluxo apresentou $0,48 \mathrm{~m} / \mathrm{s}^{-1} \mathrm{no}$ período de cheia e $0,11 \mathrm{~m} / \mathrm{s}^{-1}$ no período de estiagem.

Segundo Carvalho (2008, p. 75), no canal, de uma margem à outra e da superfície para o leito, o fluxo não flui de forma homogênea; logo, isso implica também a variação da descarga (vazão), a qual varia nas seções vertical e transversal do rio. Esse fato ocorre em virtude da morfologia do rio, cujo atrito da água, nas margens e no leito, causa um efeito de retar- 
damento da velocidade, assim como o efeito de atrito da lâmina de água superficial com a atmosfera.

O volume de água, no corredor fluvial do rio Paraguai, é definido pelas estações de cheia e de estiagem, sendo apontado por Bühler e Souza (2012, p. 345) e Souza et al. (2012, p. 88) como fator controlador do aporte de sedimentos e sua distribuição na seção transversal e ao longo do perfil longitudinal. A variação do nível da água e de vazão, que influencia no transbordamento para a planície de inundação, atua no processo de sedimentação no canal principal e no assoreamento de feições morfológicas do corredor fluvial, conforme verificado por Zani et al. (2008, p. 562), a partir de dados batimétricos.

A concentração de sedimentos suspensos pode variar de acordo com a velocidade do fluxo, ambiente fluvial e uso e ocupação do entorno. Nesse sentido, Leli et al. (2010, p. 51) afirmam que "a ocupação antrópica na bacia hidrográfica do rio Ivaí na sua mais ampla variedade tem alterado sensivelmente a concentração de sedimentos suspensos nos canais”. Desflorestamento, atividade agrícola e mineração, em geral, contribuem para o aumento da carga suspensa dos rios, ao passo que a construção de barragens e a urbanização podem influir negativamente na concentração da carga suspensa, principalmente por escoamento superficial (Leli et al., 2010, p. 51).

Na região sudoeste de Mato Grosso, a crescente ocupação populacional tem provocado o desmatamento de grande parte da vegetação natural para a exploração agropecuária, sem o adequado uso e manejo do solo, originando áreas de alta fragilidade ambiental e suscetibilidade à erosão hídrica (Neves et al., 2011, p. 59). E, ainda conforme Silva et al. (2011, p. 52), até 2008, o desmatamento na planície do Pantanal atingiu 12,14\% de sua área, já no planalto havia atingido 58,90\%. Segundo os autores, os percentuais atuais indicam que, se não houver ações de controle efetivas, a vegetação natural da região poderá ser suprimida até o ano de 2050.

Na interbacia do rio Paraguai Médio, a montante, no que tange à área do presente estudo, Pessoa et al. (2013, p. 122-123) constataram que a vegetação nativa no período analisado compõe, principalmente, as áreas de APPs ao longo do rio Paraguai, córregos Ixu e Ribeirão Queimado e as áreas de encostas das porções norte (Alto Paraguai) e leste da interbacia. Apresentam, portanto, diminuição de 19,85\% de sua área em 2001 e 
3,79\% em 2011, com aumento das áreas de pastagem, cana-de-açúcar e solo exposto.

Nesse sentido, Souza Filho (2013, p. 131) destaca outra problemática relacionada ao uso dos recursos hídricos na bacia do rio Paraguai. Conforme o autor, o conjunto de empreendimentos hidrelétricos poderá reter até $66 \%$ da carga detrítica transportada pelos rios com as barragens, o que equivale a cerca de $52 \%$ da carga afluente ao Pantanal; contudo, tais valores podem ser menores, pois o transporte de fundo não é conhecido e a retenção dos sedimentos em suspensão, em pequenos reservatórios, é pouco significativa. Tal retenção poderá contrabalançar o aumento do aporte de sedimentos proporcionado pela ocupação da bacia, mas pode também ter intensidade suficiente para dar início à degradação da planície pantaneira, caso a carga de saída do Pantanal seja maior do que a de entrada.

No período de cheia, a concentração de sedimentos em suspensão, na baía Comprida, foi de $200 \mathrm{mg} / \mathrm{L}^{-1}$ nas seções monitoradas, com descarga sólida de 1.076,08 t/dia na entrada e 978,22 t/dia na saída do canal. No rio Paraguai, no entanto, registraram-se $290 \mathrm{mg} / \mathrm{L}^{-1}$ e $180 \mathrm{mg} / \mathrm{L}^{-1}$, com descarga entre 15.412,44 t/dia e 2.111,02 t/dia, cheia e estiagem, respectivamente. Bühler e Souza (2012, p. 345) verificaram a concentração de sólidos suspensos na baía do Iate, a montante da saída da baía Comprida, que variou entre $57 \mathrm{mg} / \mathrm{L}^{-1}$ e $106 \mathrm{mg} / \mathrm{L}^{-1}$ nos períodos de cheia e de estiagem. Na baía do Malheiros, área central da cidade de Cáceres, a jusante da saída da área do presente estudo, as autoras identificaram $270 \mathrm{mg} / \mathrm{L}^{-1}$ e $84 \mathrm{mg} / \mathrm{L}^{-1}$.

A análise dos sedimentos de fundo apresentou maior quantidade de fração de areia média em todas as seções. No rio Paraguai, a concentração foi de 92,95\% e 91,3\%, e na entrada da baía Comprida foi de 86,3\%. No período de estiagem, houve um aumento na quantidade de areia grossa, com $5,95 \%$ dessa areia, sendo ainda a fração de areia média predominante nas seções transversais. Também foram identificadas frações finas de silte e argila com aumento no período de estiagem (Tabela 2). A presença de material fino nos sedimentos de fundo e barras de sedimentos pode ser associada à diminuição do nível e da velocidade da água, onde os sedimentos suspensos são depositados por decantação. Em campo, observaram-se, nos depósitos em formação, camadas superficiais de lamas (Figura 4). 

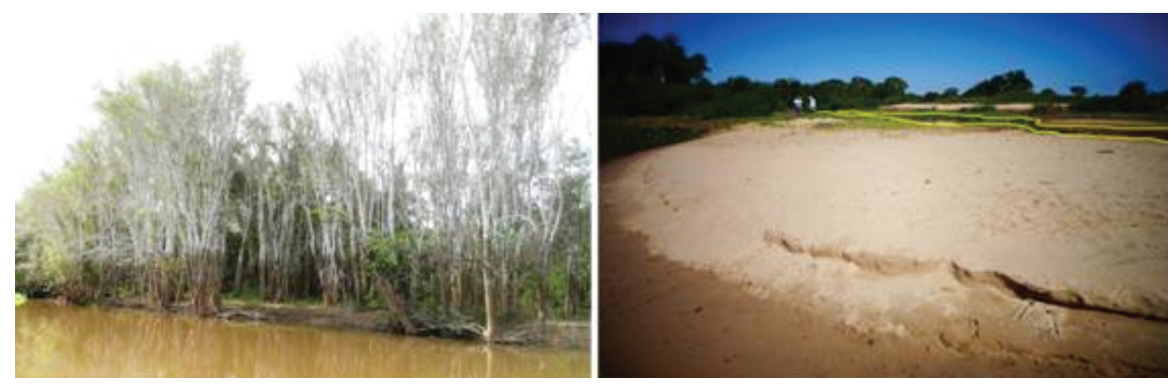

Figura 4 - Aspectos relevantes na saída da baía Comprida para diferentes períodos (registro de inundação na vegetação e barras de sedimentos).

Fonte: Os autores.

Na saída da baía Comprida, o material de fundo apresentou maior quantidade de areia em ambos os períodos. A fração de areia média, no período de cheia, foi de $95,4 \%$, com $3,75 \%$ de fração de areia grossa. O canal 1, no período de estiagem, apresentou concentração de areia média com $88,6 \%$, onde ocorreram as frações finas de silte, com $2,85 \%$, e argila, com $0,65 \%$. O canal 2 recebeu maior carga de material arenoso, com $3,85 \%$ de fração de areia grossa, $87,75 \%$ de areia média e $7,45 \%$ de areia fina (Tabela 2).

Tabela 2 - Composição granulométrica dos sedimentos de fundo transportados no corredor fluvial do rio Paraguai para os períodos de cheia (abril de 2012)

e de estiagem (outubro de 2012),

Cáceres, Mato Grosso.

\begin{tabular}{|c|c|c|c|c|c|c|}
\hline \multirow{2}{*}{ Local } & \multirow{2}{*}{ Período } & Areia Grossa & Areia Média & Areia Fina & Silte & Argila \\
\hline & & \multicolumn{5}{|c|}{ Composição em (\%) } \\
\hline \multirow{2}{*}{$\begin{array}{l}\text { Rio Paraguai - } \\
\text { montante da baía } \\
\text { Comprida } \\
\text { (Seção A) }\end{array}$} & Cheia & 2,75 & 92,95 & 4,15 & --- & --- \\
\hline & Estiagem & 0,9 & 91,3 & 7,4 & --- & 0,4 \\
\hline \multirow{2}{*}{$\begin{array}{l}\text { Entrada da baía } \\
\text { Comprida } \\
\text { (Seção B) }\end{array}$} & Cheia & 0,40 & 86,3 & 13,3 & --- & -- \\
\hline & Estiagem & 5,95 & 79,95 & 4,75 & 8,7 & 0,65 \\
\hline \multirow{3}{*}{$\begin{array}{l}\text { Saída da baía } \\
\text { Comprida } \\
\text { (Seção C) }\end{array}$} & Cheia & 3,75 & 95,4 & 0,85 & --- & +- \\
\hline & Estiagem - Canal 1 & 0,9 & 88,6 & 7 & 2,85 & 0,65 \\
\hline & Estiagem - Canal 2 & 3,85 & 87,75 & 7,45 & 0,85 & 0,1 \\
\hline
\end{tabular}

Fonte: Elaboração dos autores. 
Silva et al. (2008, p. 170), ao analisarem a composição granulométrica dos sedimentos de fundo ao longo do perfil longitudinal do rio Paraguai, concluíram que as amostras possuem grande homogeneidade textural, com domínio da classe areia média (acima de $80 \%$ ). As exceções devem-se às amostras do ponto Barranco Vermelho e do ponto Hotel Baiazinha, áreas sujeitas à dragagem. Outra exceção é o ponto Planície do Pantanal, onde o rio apresenta baixa velocidade de fluxo. Nesse sentido, as atividades econômicas desenvolvidas direta ou indiretamente no canal do rio Paraguai podem interferir na concentração e distribuição textural dos sedimentos de fundo.

Rocha e Souza Filho (2005, p. 31) concluíram que a interação entre a variação sazonal das condicionantes hidrodinâmicas e a entrada de material proveniente do rio Paraná, em seção transversal do canal Cortado, mostra-se insuficiente para o transporte contínuo de materiais entre areias médias e grossas encontradas no seu leito, permitindo a mobilização maior apenas de areias finas. Destacam ainda que tais variações são responsáveis pelo desenvolvimento de processos que concentram os sedimentos grosseiros.

E, ainda conforme Santos e Stevaux (2010, p. 607), dependendo do regime fluvial e da disponibilidade de material para transporte, a areia que está sendo transportada pode se acumular em grandes corpos submersos (barras arenosas submersas) ou eventualmente aflorar à superfície do rio. Seja qual for o tipo de barra, sua presença no rio é relativamente efêmera e sua distribuição, embora controlada pelas características do fluxo, tem um caráter aparentemente errático e varia, em geral, a cada evento de cheia, podendo ser acrescida ou desaparecer (ser transportada pelo rio).

Bayer e Carvalho (2008, p. 27) afirmam que, no rio Araguaia, a grande quantidade de areia transportada na fase final das enchentes deposita-se nas margens do canal, originando importantes depósitos que ficam separados da planície aluvial por pequenas depressões e canais pouco profundos. Nessas depressões, acumulam-se, a partir de mecanismos de decantação, materiais mais finos, escuros (silte e argilas) e restos orgânicos em decomposição.

Assim, Bayer (2010, p. 29) identificou o assoreamento de alguns canais secundários do rio Araguaia. Conforme o autor, essa rápida evolução está diretamente associada à "acelerada" dinâmica morfológica que mostra os ambientes sedimentares da planície definidos, dentre outros 
fatores, pelo suprimento de materiais. Assim, o assoreamento de canais secundários e a posterior anexação de ilhas à planície de inundação são ressaltados como os principais fatores de mudanças de padrão de canal.

No período de estiagem, a baía Comprida apresenta intenso processo de deposição de sedimentos. O assoreamento do canal está associado à própria dinâmica do rio Paraguai com o aporte de sedimentos e a diminuição do volume de água. A composição granulométrica dos sedimentos de fundo é um dos fatores que favorecem a formação de geoformas deposicionais ao longo do perfil longitudinal da baía Comprida. Na entrada do canal, identificaram-se barras lateral e central em estabilização. E na saída do canal, o processo de deposição resultou em três barras de sedimentos e depósitos ainda em formação.

Em estudo realizado no corredor fluvial do rio Paraguai, Souza et al. (2012, p. 560-562) concluíram que as mudanças nas feições morfológicas da planície e na calha do rio resultam de sua própria dinâmica. As mudanças laterais no canal, conforme os autores, resultam de alteração na direção do fluxo; surgimento de novos braços; alargamento do canal, em resposta ao acúmulo de sedimentos no leito, o que diminui a profundidade; progressiva transferência de curva de meandro e transferência da vazão do canal principal para canais secundários. Contudo, o uso do solo na bacia e no canal pode alterar significativamente o aporte de sedimentos.

\section{Considerações finais}

O monitoramento do aporte de sedimentos e hidrodinâmica, no rio Paraguai e afluentes, torna-se necessário, tendo em vista a amplitude fluviométrica com efeitos nos processos fluviais, bem como o uso da terra na bacia, que pode influenciar na dinâmica da planície pantaneira. As técnicas empregadas em campo, quando da análise em laboratório, mostraram-se eficientes para determinação das frações granulométricas dos sedimentos de fundo e concentração dos sedimentos em suspensão, em um trecho do corredor fluvial.

De forma pontual, vários autores apontam alterações em feições morfológicas (assoreamento, dragagem, desvio do fluxo com obras de engenharia) e trechos do rio Paraguai (erosão marginal, uso das margens com retirada da cobertura vegetal para construção de pontos de pesca e 
turismo), principalmente no perímetro urbano de municípios como Barra do Bugres e Cáceres, em Mato Grosso, e em suas áreas de influência.

Com relação às mudanças na morfologia de ambientes fluviais do rio Paraguai, objeto do presente estudo, sugere-se o monitoramento da vazão, transporte de sedimentos de fundo e em suspensão, aliado a outros instrumentos como, por exemplo, o monitoramento espaçotemporal, subsidiados pelas geotecnologias. Os resultados de novas pesquisas e dados sistematizados poderão auxiliar como ferramentas no planejamento e na gestão com fins ambientais e econômicos, o que, na atualidade, é insuficiente.

\section{Agradecimentos}

Ao projeto Processo de sedimentação e qualidade da água no corredor fluvial do rio Paraguai entre a foz do rio Bugres e a Estação Ecológica da Ilha Taiamã, Mato Grosso - vinculado à sub-rede de pesquisa ASA de estudos sociais, ambientais e de tecnologias para o sistema produtivo na região sudoeste mato-grossense, financiada pela REDE PRO-CENTRO-OESTE MCT/CNPq/FNDCT/FAPs/MEC/CAPES n. 031/2010 (2010- 2015) -, pelo apoio financeiro, que possibilitou os trabalhos de campo e laboratório dos quais decorre este artigo. À Coordenação de Aperfeiçoamento de Pessoal de Nível Superior (CAPES), pela concessão de Bolsa de Mestrado (2013-2015) ao primeiro autor. Também à Universidade do Estado de Mato Grosso (UNEMAT), pelo apoio logístico por meio do Laboratório de Pesquisa e Estudos em Geomorfologia Fluvial (LAPEGEOF).

\section{Referências}

BAYER, M. Dinâmica do transporte, composição e estratigrafia dos sedimentos da planície aluvial do rio Araguaia. 104 f. Tese (Doutorado em Ciências Ambientais) - Programa de Pós-Graduação em Ciências Ambientais, Universidade Federal de Goiás (UFG), Goiânia, 2010. Disponível em: <http://webcache.googleusercontent. com/search?q=cache:http://www.labogef.iesa.ufg.br/labogef/arquivos/ downloads/Maximiliano_Bayer_tese_47508.pdf>. Acesso em: 5 mar. 2014.

BAYER, M.; CARVALHO, T. M. Processos morfológicos e sedimentos no canal do rio Araguaia. Revista de Estudos Ambientais, Blumenau, v. 10, n. 2, p. 24-31, 2008. Disponível em: <http://proxy.furb.br/ojs/index.php/rea/article/view/1215>. Acesso em: 18 mar. 2013. 
BRAGA, C. C. Distribuição espacial e temporal de sólidos em suspensão nos afluentes do reservatório da usina hidrelétrica Barra dos Coqueiros, Goiás. Boletim Goiano de Geografia, Goiânia, v. 33, n. 2, p. 121-134, 2013. Disponível em: <http://www.revistas.ufg.br/index.php/bgg/article/viewFile/25560/15599>. Acesso em: 18 set. 2013.

BÜHLER, B. F.; SOUZA, C. A. Aspectos sedimentares do rio Paraguai no perímetro urbano de Cáceres (MT). Geociências, Rio Claro, v. 31, n. 3, p. 339-349, 2012. Disponível em: <http://www.revistageociencias.com.br/31_3/Art_03_Buhler_e_ Souza.pdf $>$. Acesso em: 10 mar. 2013.

CAMARGO, L. (Org.). Atlas de Mato Grosso: abordagem socioeconômico-ecológica. Cuiabá (MT): Entrelinhas, 2011. 96 p.

CARVALHO, T. M. Técnicas de medição de vazão por meios convencionais e não convencionais. Revista Brasileira de Geografia Física, Recife, v. 1, n. 1, p. 73-85, 2008. Disponível em: <http://www.revista.ufpe.br/rbgfe/index.php/revista/ article/viewFile/19/22>. Acesso em: 18 mar. 2013.

. Avaliação do transporte de carga sedimentar no médio rio Araguaia. Geosul, Florianópolis, v. 24, n. 47, p. 147-160, 2009. Disponível em: <https:/periodicos. ufsc.br/index.php/geosul/article/viewFile/12255/11711>. Acesso em: 15 mar. 2013.

CASTRILlON, S. K. I.; SILVA, C. J. da; FERNANDEZ, J. R. C.; IKEDA, A. K. Avaliação da diversidade arbórea das ilhas do rio Paraguai na região de Cáceres, Pantanal Mato-Grossense, Brasil. Acta Botanica Brasilica, Belo Horizonte, v. 25, n. 3, p. 672-684, 2011. Disponível em: <http://www.scielo.br/scielo.php?pid $=$ S0102-33062011000300021\& script=sci_arttext $>$. Acesso em: 20 mar. 2013.

CUNHA, S. B. Geomorfologia fluvial. In: CUNHA, S. B.; GUERRA, A. J. T. (Orgs.). Geomorfologia: exercícios, técnicas e aplicações. 3. ed. Rio de Janeiro: Bertrand Brasil, 2009. p. 157-189.

EMBRAPA. EMPRESA BRASILEIRA DE PESQUISA AGROPECUÁRIA. Manual de métodos de análises de solos. 2. ed. Rio de Janeiro: Embrapa Solos, 1997. 212 p.

FRANCO, A. A. Análise da dinâmica de fluxo e morfologia na confluência dos rios Ivaí e Paraná, PR/MS. 2007. 98 f. Dissertação (Mestrado em Análise Geoambiental) - Programa de Pós-Graduação em Análise Geoambiental, Universidade de Guarulhos, Guarulhos, São Paulo, 2007. Disponível em: < http://ppegeo.igc.usp. br/scielo.php?pid=S0101-90822009000100001\&script=sci_arttext $>$. Acesso em: 5 mar. 2013.

LEANDRO, G. R. S.; SOUZA, C. A. Pantanal de Cáceres: composição granulométrica dos sedimentos de fundo no rio Paraguai entre a foz do rio Cabaçal e a cidade de Cáceres, Mato Grosso, Brasil. Rev. Ambiente \& Água, Taubaté, v. 7, n. 2, p. 263-276, 2012. Disponível em: <http://dx.doi.org/10.4136/ambi-agua.876>. Acesso em: 10 mar. 2013.

LEANDRO, G. R. S.; SOUZA, C. A.; CHAVES, I. J. F. Aspectos sedimentares na baía Negra, corredor fluvial do rio Paraguai, Pantanal de Cáceres (MT). Caminhos de Geografia, Uberlândia, v. 13, n. 43, p. 204-216, 2012. Disponível em: <http://siec. unemat.br/anais/conic/impressao-resumo_expandido.php?fxev $=\mathrm{MA}==\& \mathrm{fxid}=$

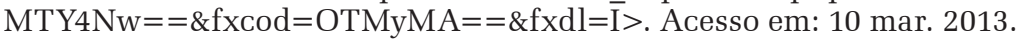


LELI, I. T.; STEVAUX, J. C.; NÓBREGA, M. T. Produção e transporte da carga suspensa fluvial: teoria e método para rios de médio porte. Boletim de Geografia, Maringá, v. 28, n. 1, p. 43-58, 2010. Disponível em: <http://www.prosul.uem. br/arquivos/Relat\%F3rio\%20 final\%20projeto\%20ARPA\%20-\%20CNPq.pdf>. Acesso em: 10 mar. 2013.

NEVES, S. M. A. S.; CRUZ, C. B. M.; NEVES, R. J. Geotecnologias aplicadas na identificação e classificação das unidades ambientais do Pantanal de Cáceres, Mato Grosso, Brasil. Geografia, Rio Claro, v. 34, n. 1, p. 795-805, 2009. Disponível em: <http://www.bib.unesc.net/arquivos/90000/94200/11_94275.htm>. Acesso em: 18 mar. 2013.

NEVES, S. M. A. S.; NUNES, M. C. M.; NEVES, R. J. Caracterização das condições climáticas de Cáceres, Mato Grosso, Brasil, no período de 1971-2009: subsídio às atividades agropecuárias e turísticas municipais. Boletim Goiano de Geografia, Goiânia, v. 31, n. 2, p. 55-68, 2011. Disponível em: <http://www.revistas.ufg.br/ index.php/bgg/article/view/16845>. Acesso em: 18 mar. 2014.

PESSOA, S. P. M.; GALVANIN, E. A. S.; KREITLOW, J. P.; NEVES, S. M. A. S.; NUNES, J. R. S.; ZAGO, B. W. Análise espaço-temporal da cobertura vegetal e uso da terra na interbacia do rio Paraguai médio, Mato Grosso, Brasil. Revista Árvore, Viçosa, v. 37, n. 1, p. 119-128, 2013. Disponível em: <http://www.scielo.br/ scielo.php?pid=S0100-67622013000100013\&script=sci_arttext $>$. Acesso em: 18 mar. 2014.

ROCHA, P. C.; SOUZA FILHO, E. E. Interações dinâmicas entre os materiais de leito de um canal secundário com o canal principal no trecho multicanal do Alto Rio Paraná, Brasil. Revista Brasileira de Geomorfologia, São Paulo, v. 6, n. 1, p. 19-32, 2005. Disponível em: <http://www.lsie.unb.br/rbg/index.php/rbg/article/ viewFile/36/34>. Acesso em: 10 mar. 2013.

ROSS, J. L. S.; FIERZ, M. S. M. Algumas técnicas de pesquisa em Geomorfologia. In: VENTURI, L. A. B. (Org.). Praticando Geografia: técnicas de campo e laboratório. São Paulo: Oficina de Textos, 2009. p. 69-84.

SANTOS, D. N.; STEVAUX, J. C. Alterações de longa duração na dinâmica hidrossedimentar por extração de areia no alto curso do rio Paraná, na região de Porto Rico, Paraná. Geociências, Rio Claro, v. 29, n. 4, p. 603-612, 2010. Disponível em: <http://www.revistageociencias.com.br/29_4/Art\%2013_Santos. pdf $>$. Acesso em: 10 mar. 2013.

SILVA, A. Padrão de canal do rio Paraguai na região de Cáceres (MT). 79 f. Dissertação (Mestrado em Geografia) - Programa de Pós-Graduação em Geografia, Universidade Estadual de Maringá (UEM), Maringá, Paraná, 2006. Disponível em: $<$ http://sites.uem.br/pge/documentos-para-publicacao/dissertacoes-1/dissertacoes -2006-pdfs/Aguinaldo__Mestrado_Final-1.pdf>. Acesso em: 5 mar. 2014.

SILVA, A.; SOUZA FILHO, E. E.; CUNHA, S. B. Padrões de canal do rio Paraguai na região de Cáceres (MT). Revista Brasileira de Geociências, São Paulo, v. 38, n. 1, p. 167-177, 2008. Disponível em: <http://www.sbgeo.org.br/pub_sbg/rbg/vol38_ down/3801 /8975.pdf>. Acesso em: 18 mar. 2014.

SILVA, E. S. F.; SOUZA, C. A.; LEANDRO, G. R. S.; ANDRADE, L. N. P. S.; GALBIATI, C. Evolução das feições morfológicas do rio Paraguai no Pantanal de 
Cáceres (MT). Revista Brasileira de Geomorfologia, São Paulo, v. 13, n. 4, p. 435442, 2012. Disponível em: <http://www.lsie.unb.br/rbg/index.php/rbg/article/ view/299/272>. Acesso em: mar. 2014.

SILVA, J. S. V.; ABDON, M. M.; SILVA, S. M. A.; MORAES, J. A. Evolution of deforestation in the brazilian pantanal and surroundings in the timeframe 19762008. Geografia, Rio Claro, v. 36, número especial, p. 35-55, 2011. Disponível em: <http://www.ageteo.org.br/index.php/geografia-vol36>. Acesso em: 17 mar. 2014.

SOUZA, C. A. Dinâmica do corredorfluvial do rio Paraguai entre a cidade de Cáceres e a Estação Ecológica da ilha de Taiamã, Mato Grosso. 173 f. Tese (Doutorado em Geografia) - Programa de Pós-Graduação em Geografia, Universidade Federal do Rio de Janeiro, Rio de Janeiro, 2004. Disponível em: <http://www.ppgg.igeo.ufrj. $\mathrm{br} /$ index.php?option $=$ com_content\&task $=$ view\&id $=541 \&$ Itemid $=49>$. Acesso em: 5 mar. 2013.

SOUZA, C. A.; PIERANGELI, M. A. P.; SOUSA, J. B. Análise espaçotemporal do corredor fluvial do rio Paraguai entre a cidade de Cáceres e a ilha Taiamã, Mato Grosso. Revista Brasileira de Cartografia, Rio de Janeiro, v. 64, n. 5, p. 551564, 2012. Disponível em: <http://www.lsie.unb.br/rbc/index.php/rbc/article/ view/464>. Acesso em: 4 mar. 2014.

SOUZA, C. A.; VENDRAMINI, W. J.; SOUZA, M. A. Assoreamento na baía do Sadao no rio Paraguai - Cáceres (MT). Cadernos de Geociências, Salvador, v. 9, n. 2, p. 85-93, 2012. Disponível em: <http://www.portalseer.ufba.br/index.php/ cadgeoc/article/view/6016>. Acesso em: 4 mar. 2013.

SOUZA FILHO, E. E. As barragens na bacia do rio Paraguai e a possível influência sobre a descarga fluvial e o transporte de sedimentos. Boletim de Geografia, Maringá, v. 31, n. 1, p. 117-133, 2013. Disponível em: <http://www.periodicos. uem.br/ojs/index.php/BolGeogr/article/view/13638>. Acesso em: 17 mar. 2013.

SUGUIO, K. Introdução à sedimentologia. São Paulo: Edgard Blücher, 1973. 307 p.

ZANI, H.; ASSINE, M. L.; SILVA, A. Batimetria fluvial estimada com dados orbitais: estudo de caso no alto curso do rio Paraguai com o sensor Aster. Geociências, Rio Claro, v. 27, n. 4, p. 555-565, 2008. Disponível em: <http://ppegeo.igc.usp.br/ scielo.php?pid=S0101-90822008000400010\&script $=$ sci_arttext $>$. Acesso em: 10 mar. 2013.

Gustavo Roberto dos Santos Leandro - Graduado em Geografia pela Universidade do Estado de Mato Grosso, Mestrando pelo Programa de Pós-Graduação em Geografia da Universidade Federal Fluminense.

Célia Alves de Souza - Licenciada e Bacharel em Geografia pela Universidade Federal de Mato Grosso do Sul, Mestre em Geografia pela Universidade Federal do Rio de Janeiro, Doutora em Geografia pela mesma Universidade, Pós-Doutora pela Universidade Federal de Viçosa, Departamento de Solos, Professora Adjunta da Universidade do Estado de Mato Grosso. 
Flávio Rodrigues do Nascimento - Licenciado e Bacharel em Geografia pela Universidade Federal do Ceará, Mestre em Geografia pela Universidade Estadual do Ceará, Doutor em Geografia pela Universidade Federal Fluminense, Professor do curso de Graduação e do Programa de Pós-Graduação em Geografia da Universidade Federal Fluminense.

Recebido para publicação em 12 de abril de 2014

Aceito para publicação em 10 de junho de 2014 